\title{
P02-117
}

\section{DAY HOSPITAL AND THEN...FOLLOW-UP TWO AND A HALF YEARS AFTER THE HOSPITALIZATION}

R. Pedrosa, V. Teixeira de Sousa, J. Marques, A. Martins, I. Domingues, L. Moura, R. Curral, A. Roma Torres

Hospital de S. João, Porto, Portugal

Psychiatry Day Hospitals deal with a wide spectrum of disorders, being responsible for a psychosocial intervention that intends to improve patient's quality of life. The Psychiatry Day Hospital Department of Hospital de São João has thirty-eight years of activity, and has been one of the first in Portugal. The aim of this Psychiatry Unit, composed by a multidisciplinary team, is to prevent relapses and rehospitalisations, promoting the patients' social rehabilitation, building a bridge between inpatient hospitalization and their re-entry into the community.

The primary objective of this cross-sectional study was to evaluate important aspects of service's quality, such as the use of health resources and results in functional terms. The authors made the follow-up of the patients that had been admitted in 2005 (Jan 2005 - Dez 2005; $n=77$ ). For this purpose, it was assessed the number of attendances to the Emergency Department and hospitalizations two and a half years before and after the treatment in Day Hospital. It was also compared their current employment situation to that which preceded the Day Hospital care.

This study was performed in clinical setting among a reduced sample, with the inherent limitations. It would be appealing to replicate this investigation in a larger population and including some other variables. 